\title{
AS MUDANÇAS CLIMÁTICAS E O COMPROMETIMENTO DA EXISTÊNCIA DA VIDA NA TERRA: A BAIXA EFICÁCIA DOS ACORDOS INTERNACIONAIS PARA A ESTABILIZAÇÃO DAS TEMPERATURAS
}

\section{THE CLIMATE CHANGE AND THE COMMITMENT OF THE EXISTENCE OF LIFE ON EARTH: THE LOW EFFECTIVENESS OF INTERNATIONAL AGREEMENTS TO STABILIZE TEMPERATURES}

\author{
${ }^{1}$ Márcia Rodrigues Bertoldi \\ ${ }^{2}$ Yasmin Lange Seoane
}

\section{RESUMO}

O presente trabalho analisa a proteção que o Direito Internacional Ambiental confere à questão do aquecimento global, principalmente no que tange à tentativa de estabilização das emissões de gases causadores do efeito estufa. Nesse sentido, o trabalho analisará, por meio das decisões das Conferências das Partes, a baixa eficácia das normas de soft law, uma vez que não são normas com caráter estritamente obrigacional e sim recomendatório. Ademais, apresenta-se as conclusões do Quinto Relatório do Painel Intergovernamental sobre Mudanças Climáticas e, nesse sentido, constata-se que o caráter soft dos documentos relativos à mudança climática são de baixa eficácia.

Palavras-chave: Aquecimento global, Direito internacional ambiental, Efeito estufa, Mudanças climáticas, Soft law

\begin{abstract}
This paper analyzes the protection that international law gives the environmental issue of global warming, especially with regard to trying to stabilize emissions of gases causing the greenhouse effect. In this sense, the work shall, through the decisions of the Conference of the Parties, demonstrate the low effectiveness of soft law standards, since they are not strictly obligatory, but yes a recommendatory character. In addition, it presents the conclusions of the Fifth Intergovernmental Panel on Climate Change Report and, accordingly, it appears that the character of the soft documents relating to climate change are of low efficiency.
\end{abstract}

Keywords: Global warming, International environmental law, Greenhouse effect, Climate changes, Soft law

\footnotetext{
${ }^{1}$ Pós-Doutora pela Universidade do Vale do Rio dos Sinos, UNISINOS, Rio Grande do Sul, RS. Professor na Universidade Federal de Pelotas - UFPEL, Rio Grande do Sul, RS.E-mail: marciabertoldi@yahoo.com

${ }^{2}$ Especiallista em andamento em Relações Internacionai na Damásio Educacional - DAMÁSIO, São Paulo, SP.Email: mymynls@hotmail.com
} 


\section{INTRODUÇÃO}

O aumento das temperaturas no Planeta vem ocasionando inúmeras consequências negativas para os sistemas naturais e humanos. Isso se verifica em virtude de um aumento exacerbado das emissões de Gases de Efeito Estufa (GEE) relacionado diretamente às atividades antropogênicas.

Esse aumento das emissões de gases se intensificou a partir da Revolução Industrial (1840), uma vez que restou comprovado o aumento da temperatura na Terra, desde a Revolução Industrial, de cerca de $1^{\circ} \mathrm{C}$, chegando até $2^{\circ} \mathrm{C}$ em determinadas regiões do globo terrestre ${ }^{1}$.

Tal aumento de temperaturas é responsável, por exemplo, pelo crescente número de queimadas em florestas, pelo derretimento de geleiras, pela desestabilização do setor alimentício, uma vez que altera o ciclo das chuvas, dificultando a irrigação e, por conseguinte, desestruturando as plantações e colheitas, o que afeta os preços e diminui a oferta. Além disso, observa-se um aumento do número de mortes causadas pelo calor excessivo em determinadas regiões, bem como se verifica o agravamento da crise hídrica em diversos países, especialmente os localizados na África e Oriente Médio.

Essas verificações são oriundas dos Relatórios de Avaliação do Painel Intergovernamental sobre Mudanças Climáticas, órgão criado no âmbito da Nações Unidas cujo objetivo é sintetizar e divulgar os conhecimentos mais avançados sobre mudanças do clima, através de relatórios publicados periodicamente. Por meio destes relatórios é possível ter-se um diagnóstico atual da situação climática da Terra, além de projeções para os próximos anos, em dois cenários prováveis: manutenção das emissões gasosas e aumento das temperaturas ou diminuição das emissões e estabilização do clima.

Nesse sentido, a comunidade internacional vem buscando formas de conter as emissões dos gases do efeito estufa e dessa maneira estancar o aumento impulsivo das temperaturas da Terra.

\footnotetext{
${ }^{1}$ Segundo o NOAA, National Centers for Environmental Information, no Relatório sobre o Estado do Clima de novembro de 2015 , esse ano foi $0,90^{\circ} \mathrm{C}$ mais quente que a média do século XX (2014, detentor do recorde anterior: $0,74^{\circ} \mathrm{C}$ ). A quebra de recorde foi geral nos continentes e oceanos de ambos os hemisférios. Os continentes, por aquecerem mais rapidamente que os oceanos, ficaram $1,33^{\circ} \mathrm{C}$ acima da média do século passado. Dos 16 anos mais quentes do registro histórico (de 1880 a 2015), somente 1998 não pertence ao século XXI. Disponível em: <https://www.ncdc.noaa.gov/sotc/global/201513>. Ademais, é importante assinalar que em notícia veiculada pelo Observatório do Clima, em março de 2016, Dados divulgados no sábado pela Nasa confirmam que fevereiro foi o mês mais quente da história desde que a humanidade iniciou os registros globais de temperatura, em 1880. A média do mês foi 1,35oC mais alta do que o período entre 1951 e 1980, batendo de longe a anomalia recorde anterior, que pertencia a janeiro de $2016(1,14 \mathrm{oC})$. O trimestre dezembro-fevereiro também é o mais quente da série, com 1,2oC (Disponível em: < http://blog.observatoriodoclima.eco.br/?p=2657\#sthash.u8SeB1kd.dpbs>.
} 
Para isso, utiliza-se de instrumentos jurídicos e políticos internacionais, que são, em sua maioria, constituídos de normas com caráter de soft law: normas de perfil recomendatório, com intuito de orientação. Essa característica, marcadamente dos tratados internacionais sobre meio ambiente, atrai a adesão dos países que, assim, comprometem-se em aplicá-los em seus direitos e políticas internas, ainda que imbuídos em um efeito de contágio.

O objetivo desse trabalho é, num primeiro momento, abordar os aspectos conceituais, com enfoque específico no tema do aquecimento global e seus elementos principais. Em segundo lugar, examinaremos os aspectos históricos das Conferências das Partes (COP) na Convenção sobre Mudanças Climáticas e os respectivos resultados de cada reunião. Ademais, se discute a baixa eficácia das normas soft e, em contrapartida, a sua importância para o Direito Internacional Ambiental. Num terceiro momento, analisaremos o Painel Intergovernamental sobre Mudanças Climáticas (IPCC), abordando sua criação e objetivos, bem como as conclusões do Quinto Relatório de Avaliação sobre Mudanças Climáticas no que diz respeito aos riscos verificados na manutenção da elevação das temperaturas e as previsões para os próximos anos.

O método de abordagem utilizado é o dedutivo e a pesquisa tem caráter qualitativo, utilizando-se sobretudo de análise documental. Também, utilizamos o método auxiliar histórico no relato das decisões das Conferências das Partes na Convenção sobre mudança climática.

\section{MUDANÇAS CLIMÁTICAS, AQUECIMENTO GLOBAL E GASES DE EFEITO ESTUFA: ASPECTOS CONCEITUAIS}

\subsection{Mudanças climáticas e aquecimento global}

A expressão mudanças climáticas, segundo a Convenção-Quadro das Nações Unidas sobre Mudanças Climáticas $\left(\mathrm{CQNUMC}^{2}\right)$, significa uma mudança de clima que possa ser direta ou indiretamente atribuída à atividade humana que altere a composição da atmosfera mundial e que se some àquela provocada pela variabilidade climática natural observada ao longo de períodos comparáveis ${ }^{3}$.

Nesse sentido, o IPCC (Glossário, 2001, p. 5.) define a mudança climática como:

[...]variação estatisticamente significante em um parâmetro climático médio ou sua variabilidade, persistindo um período extenso (tipicamente décadas ou por mais tempo). A mudança climática pode ser devido a processos naturais ou forças externas ou devido a mudanças persistentes causadas pela ação do homem na composição da atmosfera ou do uso da terra. (IPCC, 2001, p. 5.)

Importante mencionar que há uma diferença marcante entre mudança climática e variabilidade climática; essa é considerada pela Convenção Quadro como a mudança natural, 
que ocorreria mesmo sem a interferência humana, enquanto aquela seria a provocada e intensificada pelas atividades antrópicas. O conceito estabelecido pela Convenção Quadro é o mais comum, uma vez que, quando se fala em mudanças climáticas, especialmente nos canais midiáticos, refere-se justamente à intensificação de emissão de GEE pela atividade humana, principal gerador das mudanças climáticas. Assim sendo, este será o entendimento adotado no presente trabalho.

As mudanças climáticas acontecem basicamente pela emissão excessiva de GEE, oriundos de diferentes atividades como: desmatamento, práticas insustentáveis de agricultura e pecuária, atividade industrial e queima de combustíveis fósseis (petróleo, carvão mineral e gás natural) para a geração de energia.

Levantamentos realizados pelo IPCC e lançados em seu Quarto Relatório (IPCC. Quarto Relatório, 2007) apontam que devido ao aumento constante de emissões de GEE, a temperatura do Planeta subiu quase um grau centígrado nos últimos cem anos e, em algumas regiões da Terra, esse aumento chegou até dois graus. Também foi constatado que esse aumento das temperaturas vem ocorrendo de maneira mais rápida nos últimos vinte e cinco anos. A temperatura subiu em uma velocidade quatro vezes maior do que a média desde 1850 É interessante ressaltar que o IPCC contempla em seus estudos tanto as causas naturais de alterações do clima, como as atribuídas às atividades humanas; no entanto se verificou que as forças antrópicas são o fator dominante, devido ao desenvolvimento tecnológico.

\subsection{Os gases do efeito estufa}

Conforme Moraes (2010, s/n) o efeito estufa é um fenômeno natural de aquecimento térmico da Terra e imprescindível para a manutenção da temperatura do planeta em condições ideais de sobrevivência. Sem ele, a Terra teria uma temperatura em torno de quinze graus

\footnotetext{
${ }^{2}$ A Convenção-Quadro das Nações Unidas sobre a Mudança do Clima, também conhecida como UNFCCC (do inglês United Nations Framework Convention on Climate Change) é um tratado internacional resultante da Conferência das Nações Unidas para o Meio Ambiente e o Desenvolvimento (CNUMAD), realizada no Rio de Janeiro, em 1992. Este tratado tem como objetivo a estabilização da concentração de gases de efeito estufa na atmosfera em níveis que possam evitar maiores danos ao sistema climático da Terra.

${ }^{3}$ Artigo $1^{\text {o }}$. da CQNUMC. Disponível em: < http://www.mct.gov.br/upd_blob/0005/5390.pdf>.
} 
negativos, dificultando o desenvolvimento das espécies, sobrevivência dos seres vivos e dos ecossistemas. $^{4}$

O referido processo ocorre da seguinte maneira: os raios provenientes do Sol, ao serem emitidos à Terra, têm dois destinos. Boa parte deles é absorvida e transformada em calor, mantendo o planeta em uma temperatura agradável para a vida, enquanto que a outra parte, em menores proporções, é refletida e direcionada ao espaço como radiação infravermelha, em razão da ação refletora de uma camada de gases do próprio efeito. Os GEE atuam como isolantes

(CALIJURI; CUNHA, 2012).

No último século, entretanto, a concentração natural desses gases isolantes tem sido demasiadamente aumentada pela ação antrópica, e o excesso de concentração desses gases na atmosfera faz com que boa parte destes raios, que deveriam voltar para o espaço, não consigam, provocando então a elevação das temperaturas e, consequentemente, o aquecimento global.

É importante mencionar que todos os dados trazidos nos parágrafos seguintes, que aprofundam a questão do efeito estufa e dos gases causadores do efeito foram extraídos do Quarto Relatório do IPCC de 2007 (IPCC. Quarto Relatório, 2007).

O GEE mais abundante é o vapor d'água; todavia não é ele o responsável pelo aumento do efeito estufa, uma vez que a quantidade desse vapor na atmosfera é constante em virtude de um controle natural que é mantido pelos processos de condensação e evaporação. Assim sendo, não existe uma interferência desse fator no aumento das concentrações de calor, ademais de não existir impacto humano direto nos níveis de vapor d'água. Entretanto, outros gases acabam contribuindo de maneira significativa para o aumento do efeito estufa, gerando, por conseguinte, o aquecimento global: dióxido de carbono $\left(\mathrm{CO}_{2}\right)-63 \%$; metano $\left(\mathrm{CH}_{4}\right)-18,6 \%$; clorofluorcarbonos $(\mathrm{CFCs})-12 \%$; óxido nitroso $\left(\mathrm{N}_{2} \mathrm{O}\right)-6,2 \%$. capazes de reter o calor do Sol na atmosfera, formando uma espécie de capa em torno do Planeta

Todos estes valores somados, contabilizam um total de $99,8 \%$, restando apenas $0,2 \%$ para outros gases que também contribuem para o fenômeno, tendo em consideração que o nitrogênio e o oxigênio, que constituem $99 \%$ dos gases presentes na atmosfera, exercem quase nenhum efeito estufa, assim como o vapor d'água, já mencionado anteriormente.

\footnotetext{
4 "Em ecologia o ecossistema é a unidade funcional básica, uma vez que inclui tanto organismos como o ambiente abiótico, cada um deles influenciando as propriedades do outro, sendo ambos necessários para a conservação da vida tal como existe na Terra." (ODUM, Eugene Pleasants. Fundamentos de ecologia. 7. ed. Lisboa: Fundação Calouste Gulbenkian, 2004, p. 12)
} 
$\mathrm{O} \mathrm{CO}_{2}$ é o gás responsável por cerca de $63 \%$ do efeito estufa total (natural e antropogênico); além disso, é o que tem maior contribuição para o aquecimento global, ou seja, representa em torno de $77 \%$ das emissões antropogênicas mundiais. Estima-se que o $\mathrm{CO}_{2}$ tenha uma vida atmosférica de aproximadamente 105 anos, o que significa que após 105 anos a massa de $\mathrm{CO}_{2}$ na atmosfera se reduz à metade, após mais 105 anos à metade da metade e assim sucessivamente. Ou seja, tais dados indicam que as emissões deste gás no presente têm efeitos de longa duração e podem permanecer na atmosfera, provocando o câmbio climático, ao longo de vários séculos. Considerável indicar que as principais fontes de emissão deste gás são a queima de combustíveis fósseis, cerca de $82 \%$, e o desmatamento das florestas tropicais, cerca de $18 \%$.

Por sua vez, o gás metano, o segundo gás em importância nas emissões totais na atmosfera, apresenta uma vida de 12 anos e, apesar de a quantidade emitida na atmosfera ser bem menor do que o $\mathrm{CO}_{2}$, seu potencial de aquecimento é cerca de 21 vezes superior, ou seja, 1 tonelada de metano corresponde a 21 toneladas de $\mathrm{CO}_{2 \mathrm{e}}$ equivalente. ${ }^{5}$ Entre as principais fontes naturais de metano temos as emissões em áreas alagadas e por cupins ${ }^{6}$ (aproximadamente um 40\%); enquanto fontes antropogênicas, a exploração de combustíveis fósseis e as emissões pelo gado ruminante e terrenos sanitários, além de queimada de florestas e cultivo não sustentável da agricultura (aproximadamente 60\%).

Em contrapartida, o $\mathrm{N}_{2} \mathrm{O}$, cujas emissões têm origem no tratamento de dejetos animais, no uso de fertilizantes, na queima de combustíveis fósseis e também de alguns processos industriais, tem uma concentração ainda menor que o $\mathrm{CO}_{2}$ e o $\mathrm{CH}_{4}$, porém, possui um poder estufa 310 vezes maior do que o $\mathrm{CO}_{2}$, com uma meia vida longa (cerca de 114 anos) e suas concentrações têm aumentado gradativamente desde o início da era industrial, o que é bastante inquietante, já que possui um alto potencial de aquecimento, além do longo período que permanece acumulado na atmosfera.

Por fim, os clorofluorcarbonos, ou CFCs, são gases inventados e fabricados pelos seres humanos, especialmente para a produção de geladeiras, sprays e outros processos industriais. Aparecem com uma contribuição de cerca de $12 \%$ das emissões do efeito estufa. No entanto, após grandes discussões, em 1989, entrou em vigor o Protocolo de Montreal, cujo objetivo era eliminar o uso dos CFCs para esses fins até 2010; assim sendo, a presença desses gases na atmosfera vem diminuindo gradativa e exponencialmente. 


\section{ANÁlISE DA HISTÓRIA DA CONFERÊNCIA DAS PARTES DA CQMC E AS ESTRATÉGIAS DEFINIDAS NAS REUNIÕES: O AVANÇO EM MATÉRIA DE REDUÇÃO DE GEE}

A Conferência das Partes (COP), sem sede permanente, é o órgão governamental e consultivo da Convenção-Quadro sobre Mudança Climática. Tem a competência de facilitar a aplicação de estratégias de enfrentamento das mudanças climáticas, através das decisões, recomendações e alinhamentos técnicos estipulados em suas reuniões. Nestas Conferências se discute a melhor forma de lidar com as alterações do clima e implementar estratégias que poderão ser adotadas para minimizar os danos ao meio ambiente.

As decisões são tomadas por consenso entre os representantes dos governos dos países signatários da Convenção-Quadro, ou dos países que ratificaram o Protocolo de Quioto. Estes são os dois grupos com poder de voto nas reuniões. Não obstante, representantes de outros países e de organizações não-governamentais, podem participar como delegados ouvintes, ou seja, apenas acompanham as negociações. No fim de cada COP, uma série de decisões são adotadas, as quais conduzem os trabalhos do ano seguinte, que culminam na apresentação dos resultados na próxima $\mathrm{COP}$.

Cabe destacar que a base para que essas discussões ocorram anualmente ainda é o Protocolo de Quioto ${ }^{7}$. A partir deste documento é que são realizadas investigações acerca dos índices de emissão de carbono na atmosfera pelos países signatários para, então, dar início às discussões e análises dos progressos de cada Estado.

A primeira COP ocorreu em 1995 (UN. FCCC/CP/1995/7, 1995), na cidade de Berlim. A partir dela, deu-se o início às discussões e estabelecimento de prazos e metas concretas para a redução das emissões de gases do efeito estufa. Importante registrar que nessa COP, apenas os países desenvolvidos foram incluídos nas metas, já que um dos princípios do Protocolo de Quioto é o das responsabilidades comuns, no entanto diferenciadas. Portanto, os países em

\footnotetext{
${ }^{5}$ Gás Carbônico Equivalente $\left(\mathrm{CO}_{2} \mathrm{e}\right.$ ou $\mathrm{CO}_{2}$-equivalente) é o padrão comparativo entre os gases com relação aos respectivos potenciais de aquecimento global. Como os gases do efeito estufa impactam de modo distinto no clima, criou-se o $\mathrm{CO}_{2}$-equivalente como uma moeda de padronização. $\mathrm{O} \mathrm{CO}_{2}$ e é calculado multiplicando-se a quantidade de emissões de um determinado gás pelo seu efeito no clima. O IPCC conceitua: "Concentración de CO2 que daría lugar al mismo nivel de forzamiento radiativo que la mezcla dada de $\mathrm{CO} 2$ y otros gases de efecto invernadero" (IPCC. Glossário, 2001). ${ }^{6}$ Essas emissões acontecem em virtude dos processos de decomposição da vegetação e de outras matérias orgânicas em rios, represas, lagos, córregos e pântanos, bem como pela decomposição da madeira no caso dos cupins, que nada mais fazem do que dar início a um processo de decomposição de madeira ocasionando, portanto,a liberação do gás metano.
} 
desenvolvimento, que não tinham quantidades tão altas de emissão de gases de efeito estufa, ficaram de fora das metas. Relevante destacar, também, que o estabelecimento de projetos de suporte e transferência de tecnologia entre países desenvolvidos e em desenvolvimento, para tornar mais acessível o alcance das metas, foi um grande passo para a implementação do Protocolo de Quioto.

No ano seguinte, em 1996, em Genebra, ocorreu a COP-2 (UN. FCCC/CP/1996/15, 1996). Neste ano, as partes decidiram pela criação de obrigações legais para a redução das emissões mediante a Declaração de Genebra. Acordou-se que países em desenvolvimento poderiam solicitar ajuda financeira à COP através do Fundo Global para o Meio Ambiente ${ }^{8}$, com o propósito de desenvolverem programas cujo foco fosse a redução das emissões dos gases do efeito estufa.

Contudo, foi na COP-3 (UN. FCCC/CP/1997/7, 1997), no ano de 1997, no Japão, que foi assinado o Protocolo de Quioto $^{9}$, o qual estabelece reais metas de redução de GEE para os países desenvolvidos, conhecidos também como países do Anexo 1 do referido Protocolo. Nesse acordo estabeleceu-se um processo permanente de revisão, discussão e troca de informações sobre as questões climáticas do Planeta.

A quarta Conferência sobre o Clima aconteceu em 1998 na Argentina. A COP-4 (UN. FCCC/CP/1998/16, 1998) centrou seus esforços na ratificação do Protocolo assinado no ano anterior e através de seu plano de ações trouxe um programa repleto de metas para abordar alguns itens específicos do Protocolo de Quioto, seguida da COP-5 (UM. FCCC/CP/1999/6,

\footnotetext{
${ }^{7}$ Tão logo da entrada em vigor do Acordo de Paris, de 12 de dezembro de 2015 , aprovado na $21^{\circ}$ COP, este será a referência. O Acordo de Paris tem como objetivo (artigo $2^{\circ}$ ) o reforço da implementação da CQMC através de: (a) Assegurar que o aumento da temperatura média global fique $2^{\circ} \mathrm{C}$ acima dos níveis pré-industriais e prosseguir os esforços para limitar o aumento da temperatura a $1,5^{\circ} \mathrm{C}$ acima dos níveis pré-industriais, reconhecendo que isto vai reduzir significativamente os riscos e impactos das alterações climáticas; (b) Aumentar a capacidade de adaptação aos impactos adversos das alterações climáticas e promover a resiliência do clima e o baixo desenvolvimento de emissões de gases do efeito estufa, de maneira que não ameace a produção de alimentos;(c) Criar fluxo financeiros consistentes na direção de promover baixas emissões de gases de efeito estufa e o desenvolvimento resistente ao clima.

${ }^{8}$ O Fundo Global para o Meio Ambiente foi apresentado na reunião de Paris, em novembro de 1990, como um Programa Piloto para auxiliar os países em desenvolvimento na implementação de projetos que buscassem soluções para as preocupações globais em relação à proteção dos ecossistemas e à biodiversidade. Para mais informações, ver: < http://www.globalenvironmentfund.com/>
} 
1999) em Bonn, cujo destaque foi a execução do Plano de Ações de Buenos Aires da COP-4 ${ }^{10}$ (neste Plano foi elaborado um programa de metas para que algumas questões do Protocolo de Kyoto fossem tratadas separadamente como, por exemplo, mecanismos de financiamento de recursos e de transferência de tecnologia).

A sexta COP foi dividida em duas fases devido à grande dificuldade de a comunidade internacional entrar num consenso em torno das questões de mitigação dos efeitos da mudança climática. A primeira parte da COP-6 (UN. FCCC/CP/2000/5, 2000), em 2000, aconteceu em Haia, e após as discussões foram criados mecanismos de compra de carbono para facilitar o alcance das metas do Protocolo de Quioto. Entretanto, nas últimas horas de negociações, a União Europeia e os Estados Unidos não chegaram num consenso, ocasionando a suspensão da COP que, por fim, finalizou em 2001. Finalmente, após exaustivas discussões foi aprovado o uso de sumidouros ${ }^{11}$ para o cumprimento das metas de emissão e também discutidos limites de emissão e assistência financeira dos países desenvolvidos.

Por sua vez, a COP-7 (UN. FCCC/CP/2001/13, 2001), em Marrakesh, ainda em 2001, aprovou os Acordos de Marrakesh e a definição de mecanismos capazes de limitar o uso de créditos de carbono gerados pelos projetos florestais do Mecanismo de Desenvolvimento

Limpo $^{12}$. Além disso, novamente voltou-se a incentivar financeiramente os países em desenvolvimento a investirem em projetos de adaptação às mudanças climáticas.

O ano de 2002 foi marcado não só pela COP-8 (UN. FCCC/CP/2002/7, 2002) em Nova Déli, como também pela Cúpula Mundial sobre Desenvolvimento Sustentável (RIO+10). Este encontro influenciou as discussões da COP na Índia acerca do estabelecimento de metas para o uso de fontes renováveis na matriz energética dos países. Não obstante, a COP-8 foi marcada pela adesão da iniciativa privada e de organizações não governamentais, que apresentaram projetos para a criação do mercado de créditos de carbono.

\footnotetext{
${ }^{9} \mathrm{O}$ Protocolo somente entrou em vigor no ano de 2005, quando pelo menos 55 partes da Convenção-Quadro, as quais também deveriam contabilizar $55 \%$ das emissões totais de dióxido de carbono na década de noventa, ratificaram o Protocolo. Ressalta-se que os Estados Unidos e a China não ratificaram o Protocolo e são dois dos países que mais emitem GEE.O objetivo central do Protocolo de Quioto está delineado no artigo $2^{\circ}$ que estabelece a limitação e redução de emissões assumidos no artigo 3, a fim de promover o desenvolvimento sustentável.

10 Íntegra:< http://ssc.undp.org/content/dam/ssc/documents/Key\%20Policy\%20Documents/BAPA.pdf>

${ }^{11}$ Os sumidouros realizam o sequestro de carbono, atuam como ralos, retirando da atmosfera mais carbono do que emitem. São sumidouros de carbono as florestas e os oceanos sobretudo.
} 
Em Milão realizou-se, no final do ano de 2003, a nona COP (UN. FCCC/CP/2003/6, 2003), momento em que novamente foi pauta de debates a regulamentação de sumidouros de carbono no âmbito do Mecanismo de Desenvolvimento Limpo e foram estabelecidas regras para a condução de projetos de reflorestamento, as quais se tornaram condições e canais para a obtenção de créditos de carbono.

A COP-10 (UN. FCCC/CP/2004/10, 2004) foi concretizada novamente na Argentina, em 2004. As partes entraram em consenso ao estabelecer regulamentações de projetos no âmbito do Mecanismo de Desenvolvimento Limpo de pequena escala de reflorestamento, além de regras para a implementação do Protocolo de Quioto, que até então não havia entrado em vigor. Ficou claro para as partes, neste encontro, que havia urgente necessidade de metas mais rigorosas.

Em 2005, no Canadá, foi realizada a COP-11 (UN. FCCC/CP/2005/5, 2005), juntamente com a primeira Conferência das Partes no Protocolo de Quioto, que entrou em vigor no início do mesmo ano com a ratificação da Rússia. No encontro, entrou em pauta a discussão do segundo período do Protocolo, após 2012, para o qual instituições europeias defenderam reduções de emissão dos GEE na ordem de $20 \%$ a $30 \%$ até o ano de 2030 e entre $60 \%$ e $80 \%$ até 2050. Importante ressaltar que foi a primeira vez que foi colocada, oficialmente, em pauta, a questão das emissões provenientes do desmatamento tropical e das mudanças no uso da terra.

Em 2006, em Nairóbi, na COP-12 (UN. FCCC/CP/2006/5, 2006), financiamentos de projetos de adaptação para países em desenvolvimento e a revisão do Protocolo de Quioto foram os grandes destaques desta Conferência. Neste encontro, o Brasil propôs oficialmente a criação de um mecanismo que promovesse efetivamente a redução de emissões de GEE oriundas do desmatamento, que mais tarde se tornaria a proposta de redução de emissões para o desmatamento e degradação. A COP-13 (UN. FCCC/CP/2007/6, 2007), aconteceu em Bali, em 2007, quando foram estabelecidos compromissos transparentes e verificáveis para a redução dos níveis de emissão causados pelo desmatamento das florestas tropicais; o texto final da

\footnotetext{
${ }^{12} \mathrm{O}$ Mecanismo de Desenvolvimento Limpo (MDL) é um dos instrumentos de flexibilização criados pelo Protocolo de Quioto para auxiliar o processo de redução de emissões de GEE ou de captura de carbono (ou sequestro de carbono) por parte dos países do Anexo I.
} 
reunião denominou-se Mapa do Caminho de Bali. ${ }^{13}$

Poznan, em 2008, foi a sede da COP-14 (UN. FCCC/CP/2008/7, 2008), que ficou como um meio termo entre a COP-13 e as expectativas para a COP-15, tendo em vista as grandes modificações no cenário político mundial com a eleição do presidente dos Estados Unidos, Barack Obama. O avanço mais significativo desta reunião partiu das nações em desenvolvimento como Brasil, China, Índia, México e África do Sul, que demonstraram abertura para a assunção de compromissos obrigatórios de redução de emissão de carbono.

Em 2009, Copenhague, houve a tentativa de implementação do Acordo de Copenhague, mas não foi aprovado pela totalidade das Partes da Conferência. Esta foi a grande expectativa da COP-15 (UN. FCCC/CP/2009/11, 2009), pois tinha o objetivo de estabelecer um tratado que substituísse o Protocolo de Quioto. Em verdade, uma atmosfera de expectativas pairava sobre esta Conferência, não somente por sua importância, mas também pelo contexto das discussões sobre mudanças climáticas, ou seja, refletidas no impasse entre países desenvolvidos e em desenvolvimento para o estabelecimento de metas de redução das emissões e sobre bases para o esforço global no intuito de adaptação às mudanças do clima. A grande esperança era o novo presidente dos Estados Unidos, Barack Obama, mas os resultados, pelo menos para este encontro foram decepcionantes e a nenhuma conclusão concreta se chegou.

No México, na cidade de Cancún, ocorreu, no final de 2010, a COP-16 (UN. FCCC/CP/2010/7, 2010), sem muitas expectativas, após o fracasso em Copenhague. No entanto, para a surpresa de todos, uma série de acordos foram fechados. Entre eles, pode-se destacar a criação do Fundo Verde do Clima $^{14}$ e a manutenção da meta fixada na COP anterior de limitar a um máximo de $2^{\circ} \mathrm{C}$ a elevação da temperatura média em relação aos níveis préindustriais. Foi também neste encontro, que o Brasil lançou sua Comunicação Nacional de Emissões de Gases do Efeito Estufa e anunciou a regulamentação da Política Nacional acerca da Mudança Climática, através do Decreto $n^{\circ} 7.390 / 2010$, fazendo com que o país fosse a primeira nação a assumir formalmente limites de reduções de emissões de carbono.

No ano de 2011 acontece a COP-17 (UN. FCCC/CP/2011/9, 2011), em Durban, na África do Sul. No momento em que as autoridades reconheceram a necessidade de variações

\footnotetext{
13 Íntegra: 〈https://www.scribd.com/fullscreen/7485985?access_key=key-2188sxkrc8z4c431wa0p>

14 Criado para ajudar a financiar os países pobres a desenvolverem mecanismos de adaptação às mudanças climáticas e contenção das emissões dos gases do efeito estufa.
} 
para minimizar problemas decorrentes das mudanças climáticas, os Estados concordaram na definição de metas para o ano de 2015, as quais deverão ser colocadas em prática a partir de 2020. Desta forma nasceu a Plataforma de Durban.

Outras quatro Conferências das Partes aconteceram após a COP-17. A COP-18 (UN. FCCC/CP/2012/8, 2012), que foi realizada em Doha, em 2012, deixou muito a desejar. Nesse sentido, um acordo foi fechado às pressas entre os países participantes para combater o aquecimento global até 2020. Foi um ato aflito, já que as negociações adentravam a madrugada após estourar o prazo limite sem que houvesse de fato um consenso. Na tentativa de evitar o fracasso do encontro, foi apresentado um texto de compromisso para intensificar os esforços, nas palavras do então vice-primeiro-ministro do Catar, Abdullah al-Attiya, que presidia a COP.

A Conferência das Partes de número 19 (UN. FCCC/CP/2013/10, 2013) ocorreu no ano de 2013, em Varsóvia, e teve como objetivo principal preparar o terreno para que a seguinte fosse satisfatória. Este encontro foi fundamental para a discussão das bases que teceriam o compromisso global, no entanto terminou sem grandes conclusões e sem motivos para comemorações. Em 2014, aconteceu em Lima, a COP-20 (UN. FCCC/CP/2014/10, 2014). O principal objetivo desta COP era a elaboração de um rascunho para o novo acordo global, aprovado em novembro de 2015, em Paris, na COP-21 (UN. FCCC/CP/2015/10, 2015): o Acordo de Paris, um substituto ao frustrado Protocolo de Quioto.

\section{EFICÁCIA LIMITADA DAS NORMAS COM CARÁTER DE SOFT LAW VESUS SUA IMPORTÂNCIA NA ESFERA DO DIREITO INTERNACIONAL AMBIENTAL}

O que se nota, a partir dessa breve análise histórica é a baixa eficácia das normas criadas a partir das COPs e também dos acordos internacionais em matéria de meio ambiente.

Decerto, não se pode deixar de observar que os resultados obtidos com acordos internacionais que envolvem a questão climática são rasos e desestimulantes. Se por um lado tem-se a evolução diplomática das discussões acerca das alterações do clima, por outro, tevese um panorama de pouquíssimas transformações na direção de alcançar, na prática, os objetivos estabelecidos no Protocolo de Quioto, por exemplo.

Ocorre que, o Direito Internacional Ambiental, além de se manifestar como um direito positivado (hard law), com obrigações claras e definidas, se apresenta, predominantemente, em forma de direito flexível (soft law), presente especialmente nos casos em que é impossível 
vançar regras impositivas e tradicionais, e que mesmo que fossem estabelecidas não lograriam, com eficiência, êxito.

Alguns autores como Lang, afirmam que as normas em caráter de soft law, são o verdadeiro "Cavalo de Tróia" do Direito Internacional Ambiental, isso porque, apesar de sua aparência inofensiva, uma vez respaldadas pelo apoio expressivo da comunidade internacional têm uma potência obrigacional muito forte através da pressão moral externa. (LANG, 1984, p. 178)

Encontra-se na doutrina as mais diversas definições para o conceito de soft law. A definição de Thibierge (2003, p. 9) é a mais razoável, isto porque defende que os instrumentos de soft law são compostos por três vieses: mole, fluido e doce, o que significa dizer que quando estas normas forem construídas de maneira vaga e imprecisa, serão fluídas, quando não forem obrigatórias, serão doces e, em não prevendo sanções, serão moles. Ou seja, um instrumento jurídico poderá ser triplamente soft, quanto ao conteúdo, obrigatoriedade e efeitos, ou ainda poderá ser soft em apenas uma ou duas facetas.

Juste Ruiz (1999, p. 47) explica os motivos do surgimento e do fortalecimento do uso das normas de soft law:

[...] numerosas razões sociológicas, políticas e jurídicas explicam seu surgimento, consolidação e desenvolvimento crescente; a saber, o impacto dos métodos normativos empregados pelos organismos internacionais, as divergências de interesses entre países desenvolvidos e países em desenvolvimento (o que leva ambos a refutar regras muito rigorosas ou rígidas) e a incessante e rápida evolução da situação impulsionada pelo constante desenvolvimento da ciência e da tecnologia (que aconselha a adoção de normas flexíveis, suscetíveis de acomodar-se às mudanças na medida em que vão se produzindo.(tradução nossa)

Nesse sentido, Paolillo (1998, p. 394) complementa:

[...] nas normas de soft law podem aparecer em instrumentos de natureza obrigatória, como tratados, contudo formulados de um modo tão geral ou ambíguo que não podem ser interpretados como imposição de obrigações. Mais que regras jurídicas, parecem ser declarações políticas, que oferece aos Estados ampla discricionariedade para interpretá-las e aplicá-las[...] (tradução nossa)

Apesar de essenciais, a problemática gira em torno do fato de que esse tipo de norma, contida nestes instrumentos internacionais são, na sua maioria, flexíveis, uma vez que evitam usar expressões que manifestem obrigação de resultado, muito menos coação. Isto posto, os verbos mais utilizados são: promover, procurar, facilitar. Não apenas, ainda são complementados com locuções como: na medida do possível, conforme o caso, de acordo com suas condições peculiares. Se por um lado, essa característica respeita as capacidades individuais de cada Estado, por outro, acaba debilitando ainda mais o conteúdo imperativo 
encastoado nesses documentos, que já é parco. Esses instrumentos possuem um caráter mais preventivo que repressivo, pelo menos inicialmente, portanto são recomendatórios.

No entanto, "é justamente esta diversidade e flexibilidade que lhe dão maior possibilidade de se expandir"(VARELLA, 2003, p. 28), assim sendo, esta flexibilização, que em outros ramos da ciência jurídica são vistas como uma entropia do direito, no âmbito do Direito Internacional Ambiental é tida como um impulso de solução de conflitos dos temas que urgem serem solucionados e regulamentados o quanto antes, como é o caso do aquecimento global.

É interessante ressaltar que as normas criadas através dessa sistemática vislumbram alcançar tendências comportamentais futuras e não necessariamente a eficácia imediata, mas sim uma eficácia a médio e longo prazo. Ora, os instrumentos soft atraem um maior número de adesões do que os instrumentos hard, justamente pela característica de serem flexíveis, não imperativos. Desta forma, o descumprimento de um instrumento soft, não ocasionaria ilícito algum, diferentemente do descumprimento de um documento hard. Partindo desta premissa, os textos flexíveis permitem regular temas delicados que possivelmente não seriam acordados de outra maneira.

Kolb (2003) destaca que a utilização desta sistemática demonstra a emergente complexidade da comunidade internacional e de conciliação de seus interesses, assim sendo, a incapacidade das fontes tradicionais de direito de regulamentarem determinados temas em que as normas macias têm predominado.

$\mathrm{Na}$ direção de defender essa sistemática das normas macias, Soares (2003, p. 92) sustenta existir duas finalidades: "a) fixar metas para futuras ações políticas nas relações internacionais; b) recomendar aos Estados adequarem as normas de seu ordenamento jurídico interno às regras internacionais contidas na soft law". Logo, estas normas tendem a servir como primeiro passo no sentido de evolução futura para a construção de instrumentos de hard law.

\section{PAINEL INTERGOVERNAMENTAL DE CÂMBIO CLIMÁTICO (IPCC)}

\subsection{Criação e objetivos}

O IPCC foi criado em 1988, por iniciativa do Programa das Nações Unidas para o Meio Ambiente (PNUMA) e da Organização Mundial Meteorológica (OMM) com a finalidade de proporcionar avaliações integrais do estado e dos conhecimentos científicos, técnicos e socioeconômicos acerca das mudanças climáticas, suas causas, possíveis efeitos e estratégias de resposta ao fenômeno. 
É um órgão científico que examina e avalia a mais recente bibliografia técnica, científica e socioeconômica que é produzida ao redor do mundo pertinente à questão das mudanças climáticas; o órgão é responsável pelo levantamento de informações, mas não se dedica em momento algum a fiscalizações e nem supervisiona os dados e parâmetros relativos ao clima.

\section{O próprio painel traz como objetivos}

[...] analisar de forma exaustiva, objetiva, aberta e transparente as informações científicas, técnicas e socioeconômica relevantes para entender a base a científica do risco que representa o câmbio climático provocado pela atividade humana, suas possíveis repercussões e opções que existem para adaptarmo-nos às mudanças climáticas e atenuar seus efeitos. Os informes do IPCC serão neutros desde o ponto de vista político, embora devam ser abordados de forma objetiva fatores socioeconômicos, científicos e técnicos relevantes para a aplicação de certas políticas específicas. Uma peça chave do processo do IPCC é o exame. Dado que o IPCC é um órgão governamental, o exame de documento do IPCC incluirá tanto o exame realizado por especialistas da área como os realizados pelos governos. (Tradução nossa $)^{15}$

Atualmente é composto por 195 países. As reuniões dos cientistas encarregados das pesquisas ocorrem pelo menos uma vez ao ano, em sessão plenária, com a presença de representantes dos governos que compõe o Órgão. Salienta-se que devido ao seu caráter científico e intergovernamental proporciona informação científica rigorosa e equilibrada de modo que os governos reconhecem o conteúdo científico dos informes sem embargos, tornando possível a adoção de políticas neutras e ao mesmo tempo incisivas. Atualmente, o IPCC é dividido em três grupos de trabalho (GT-I, GT-II, GT-III) ${ }^{16}$ e um Grupo Especial ${ }^{17}$ que é responsável por formular e aperfeiçoar uma metodologia para o cálculo e a quantificação das emissões e absorções dos GEE.

\footnotetext{
${ }^{15}$ Disponível em: <http://www.ipcc.ch/pdf/ipcc-principles/ipcc_principles_spanish/ipcc_principles_es.pdf> Acesso em: 01 de outubro de 2015.

${ }^{16} \mathrm{O}$ GT I avalia os aspectos científicos do sistema climático e as suas alterações. Os principais temas abordados por este GT são: mudanças nos GEE e aerossóis na atmosfera; alterações observadas no ar, nas temperaturas terrestres e oceânicas, nas chuvas, nas geleiras e camadas de gelo, nos oceanos e no nível do mar; analisa também a perspectiva histórica acerca das mudanças do clima e, além disso, estabelece projeções climáticas e causas das mudanças climáticas. O Grupo de Trabalho II cuida da vulnerabilidade dos sistemas naturais e socioeconômicos às mudanças climáticas, das suas consequências positivas bem como negativas e das opções para se adaptar ao novo panorama. Este grupo também trabalha com a relação existente entre vulnerabilidade, adaptação e desenvolvimento sustentável. Para a realização destas avaliações são considerados setores (recursos hídricos; ecossistemas; produção de alimentos e florestas; sistemas costeiros, indústria e saúde humana) e regiões (África, Ásia, Austrália e Nova Zelândia, Europa, América Latina, América do Norte, Regiões Polares e Pequenas Ilhas). Por fim, o GT III avalia as opções para mitigar as alterações do clima por meio da limitação das emissões de GEE e do aumento das atividades de sua retirada da camada atmosférica. Os principais setores avaliados são: energia; transportes; construção; indústria; agricultura; silvicultura e gestão de resíduos. O Grupo analisa os custos e
} 
benefícios das diferentes abordagens para a mitigação considerando, também, os instrumentos disponíveis e as medidas políticas possíveis.

Deve-se lembrar que o Painel já publicou cinco relatórios de avaliação das mudanças climáticas: 1990, 1995, 2001, 2007 e o último, publicado em $2014^{18}$. Este último é o relatório que mais nos interessa no presente trabalho e que será tratado no próximo ponto.

\subsection{0 último relatório, de número cinco, realizado em 2014}

Nessa subseção analisaremos o Quinto Relatório do IPCC realizado pelo GT-II, cuja tradução foi autorizada pela ONU (IPCC, Quinto Relatório, 2014); importante registrar que os outros dois relatórios de avaliação do clima, dos GTs I e III, contêm informações técnicas, destinadas à cientistas e especialistas. Sendo assim, os dados trazidos pelo GT-II são os mais interessantes e congruentes com a proposta deste trabalho.

O Quinto Relatório confirma a notícia, já conhecida, de que as mudanças climáticas têm causado impactos em todos os continentes, bem como nos oceanos; evidências apontam que as alterações do clima são mais fortes e mais abrangentes nos sistemas naturais. No entanto, algumas mudanças sobre os sistemas humanos também vêm sendo atribuídas às alterações do clima.

Em boa parte das regiões, aponta o relatório, a mudança de precipitação e derretimento do gelo estão alterando os sistemas hidrológicos, ou seja, os recursos hídricos, tanto em relação à quantidade, como em relação à qualidade (confiança média ${ }^{19}$. A expectativa é de que as geleiras continuem a encolher em quase todo o mundo, justamente em virtude do aquecimento do Planeta, afetando, desta forma, o escoamento desses volumes de água (aumento dos níveis dos oceanos que, consequentemente, ocasionarão o desaparecimento de pequenas ilhas e cidades litorâneas (confiança alta).

\footnotetext{
${ }^{17}$ O Grupo Especial é responsável por desenvolver e aperfeiçoar uma metodologia para o cálculo e a quantificação das emissões e absorções dos GEE.

${ }^{18}$ Veja-se os relatórios originais no site do IPCC: < http://www.ipcc.ch/index.htm>

${ }^{19} \mathrm{~A}$ confiança na validade de uma constatação sintetiza a avaliação da prova e concordância. Níveis de confiança incluem cinco eliminatórias: muito baixo, baixo, médio, alto e muito alto. Isso significa o grau de concordância das informações analisadas entres os especialistas.
} 
$\mathrm{O}$ aumento das temperaturas está causando o descongelamento do permafrost ${ }^{20} \mathrm{em}$ regiões localizadas em altas altitudes (alta confiança). Além disso, diversas espécies, tanto terrestres quanto aquáticas, mudaram suas distribuições geográficas, suas atividades sazonais, seus padrões de migração, seu quantum e suas interações intraespecíficas (confiança alta). Até mesmo em relação à extinção de espécies foi percebido que durante os últimos séculos, as mudanças climáticas oriundas de causas antropogênicas causaram mudanças significativas nos ecossistemas e extinção de espécies (confiança alta).

$\mathrm{Na}$ agricultura, são observados muitos impactos negativos e o que torna essa evidência mais forte é que foram registradas quedas nas produções globais de milho, trigo, arroz e soja, e em consequência disso (média confiança) e desde o quarto relatório (2007), os preços no setor alimentício aumentaram rapidamente.

Foi registrado também um aumento de mortalidade relacionado ao calor e uma diminuição de mortalidade relacionada ao frio em algumas regiões, como resultado do aquecimento (média confiança). As diferenças na vulnerabilidade e exposição surgem de fatores mais relacionados com as desigualdades multidimensionais produzidas, na maioria das vezes, pelo processo desigual de desenvolvimento e distribuição de riquezas (confiança muito alta); isto porque as pessoas marginalizadas social, institucional, cultural, política e economicamente são mais vulneráveis às alterações do clima e menos propensas de adaptação e mitigação dessas mudanças. ${ }^{21}$ Essa vulnerabilidade tratada pelo Relatório não está ligada à causa específica, mas sim a um apanhado de fatores da interseção de processos sociais como a discriminação de gênero, de classe, de etnia, de idade ou de alguma deficiência física, por exemplo.

O Relatório se preocupa em destacar que os riscos relacionados às mudanças do clima, afetam diretamente a vida da população mundial pobre por meio dos impactos na indústria alimentícia, que se torna cada vez mais escassa e mais onerosa, tornando inviável a sobrevivência (lembrando que se trata de casos de extrema pobreza enfrentada, especialmente, no Continente Africano, no Oriente Médio e alguns países da América Latina).

\footnotetext{
${ }^{20}$ O permafrost ou pergelissolo (em português) é um tipo de solo encontrado na região do Ártico, constituído por terra, gelo e rochas permanentemente congelados. Esta camada é recoberta por uma camada de gelo e neve que, no inverno, chega a atingir 300 metros de profundidade em alguns locais e, no verão, reduz-se de 0,5 a 2 metros, tornando a superfície do solo pantanosa, já que as águas não são absorvidas pelo solo congelado.
} 
Eventos climáticos como secas, ondas de calor, inundações, ciclones, incêndios florestais, terremotos, ciclones e outros, evidenciam a vulnerabilidade dos sistemas naturais no que tange à exposição às mudanças climáticas (confiança muito alta). Para todos os países, as consequências desses fenômenos climáticos são desastrosas e isso evidencia a falta de preparo da nossa espécie para com essa variabilidade climática que nós mesmos ocasionamos.

Por fim, analisa o Relatório que os conflitos violentos, como os que se produzem no Oriente Médio aumentam ainda mais a vulnerabilidade às mudanças climáticas porque os conflitos em grande escala prejudicam os ativos que facilitariam a promoção da adaptação das mudanças do clima como a infraestrutura, as instituições, os recursos naturais, o capital social e as oportunidades de subsistência; ou seja, a desestabilização de uma nação afeta todas as demais na tentativa de estabilização das temperaturas no Planeta (alta confiança).

\subsection{Um diagnóstico alarmante e mudanças consideradas irreversíveis: há mundo por vir?}

Como podemos observar, o diagnóstico trazido pelo Quinto Relatório é muito preocupante e a maioria das estimativas é considerada de confiança alta ou confiança muito alta. Além disso, os principais riscos são os impactos potencialmente graves que, de acordo com o artigo segundo da Convenção-Quadro (que diz que a interferência antropogênica é perigosa para o sistema climático), são causados pelas ações antrópicas e desestruturam todos os sistemas naturais, bem como os humanos edificados.

O Relatório aponta riscos específicos em cada região do globo terrestre, mas também aponta riscos identificados como de alta confiança e que atravessam setores e regiões, ou seja, atingem a todos de forma igual. São riscos generalizados os descritos nas páginas 17 a 21 do Relatório analisado ${ }^{22}$.

\footnotetext{
21 A Agenda 2030 traz como primeiro objetivo acabar com a pobreza em todas as suas formas, em todos os lugares. Ver: < http://nacoesunidas.org/pos2015/ods1/>.

${ }^{22}$ Risco de morte; ferimentos; problemas de saúde e meios de subsistência limitados em zonas litorâneas de pequenos países insulares em desenvolvimento ou em pequenas ilhas, causados por tempestades, inundações costeiras e aumento do nível do mar; graves problemas de saúde e dificuldade de subsistência das grandes massas urbanas devido às inundações em regiões do interior; riscos sistêmicos em virtude de catástrofes climáticas extremas que desestabilizam redes de infraestrutura e serviços essenciais como energia elétrica, abastecimento de água e assistência à saúde; aumento das taxas de mortalidade e morbidade no decorrer de períodos de extremo calor, principalmente em populações urbanas vulneráveis como os que trabalham ao ar livre e em zonas rurais; insegurança alimentar e quebra de cadeias produtivas de base (arroz, soja, trigo e milho), que são ocasionadas pelo aquecimento, pelas secas, pelas inundações e pelas precipitações abundantes, especialmente para os produtores mais pobres; perda dos meios de renda em áreas rurais, por falta de água para irrigação, reduzindo as produções dos pequenos agricultores e pequenos pecuaristas; perda de ecossistemas marinhos e costeiros; perda de biodiversidade e recursos naturais essenciais às comunidades costeiras, principalmente pequenas colônias de pescadores; e perda de ecossistemas terrestres e recursos naturais também essenciais à subsistência de pequenas comunidades
} 
Relatório de avaliação traz, posteriormente ao panorama geral, uma visão mais específica respeito a alguns setores determinados, como, por exemplo, no que diz respeito aos recursos de água doce: os riscos de escassez de água doce aumentam conforme aumentam as concentrações de GEE; a fração da população mundial que sofrerá com a falta de água potável crescerá; e o número de inundações também aumentará em virtude do aumento dos níveis dos mares e oceanos, ocasionados pelo derretimento das geleiras.

Outro sistema também avaliado pelos especialistas é o sistema costeiro e de áreas baixas, em que o aumento do nível do mar projetado para o século XXI prevê impactos adversos como submersão de áreas baixas, inundações e erosões costeiras. A exploração humana sobre os ecossistemas costeiros também aumentará em virtude do aumento da concentração humana nessas áreas, que tendem a crescer nas próximas décadas, conforme os informes. Em suma, as regiões litorâneas estão altamente comprometidas.

Para os sistemas marinhos estima-se uma redução considerável na biodiversidade em regiões mais sensíveis como nos trópicos e mares semifechados. Além disso, prevê-se um deslocamento de espécies para áreas diferenciadas em razão das temperaturas. Haverá a expansão progressiva das zonas mínimas de oxigênio, consideradas também de zonas mortas, já que quase nenhuma espécie sobrevive nestas condições. Ademais, no cenário de altas e médias emissões, a acidificação dos oceanos traz riscos significativos para alguns ecossistemas como os recifes de coral e áreas polares.

As mudanças climáticas afetarão todos os aspectos da segurança alimentar, incluindo o acesso à alimentação e à estabilidade dos preços. O Relatório salienta que o aumento da temperatura associado ao crescimento da população mundial e ao consequentemente aumento da demando por alimentos, resultará em uma crise de segurança alimentar, que afetará principalmente as populações mais pobres, prejudicando, nesse sentido, a estabilidade política internacional.

Por fim, aponta ser difícil traçar estimativas para o setor de economia, já que é muito dinâmico e de rápida adaptação; no entanto, prevê uma diminuição do crescimento econômico, ou seja, uma estagnação da economia mundial e como consequência tornará mais difícil a redução da pobreza e das desigualdades.

Também, conclui que as perspectivas para os caminhos resilientes ao clima e para o desenvolvimento sustentável estão relacionadas fundamentalmente com a condição de que o mundo cumpra com a mitigação das mudanças climáticas (alta confiança). 


\section{CONSIDERAÇÕES FINAIS}

A substituição do modelo de desenvolvimento capitalista e o que ambicionamos atualmente, o modelo de desenvolvimento sustentável, se mostra a alternativa mais apropriada para a redução das emissões de GEE e, consequentemente, para a estabilização das temperaturas na Terra.

É através de instrumentos jurídicos - em parceria com órgãos destinados ao controle da situação climática do Planeta, como as COPs e o IPCC - que se torna possível a cobrança e efetivação de políticas públicas que auxiliem a necessária mudança de paradigmas em se tratando de modelos de desenvolvimento, no qual se passaria de uma economia capitalista para um economia ecológica, afinal, entende-se que esta é a alternativa para evitar o colapso do sistema e a efetivação do cenário previsto pelo Quinto Relatório do IPCC, abordado no ponto quatro.

Pode-se observar que as negociações sobre essa temática vêm evoluindo devido ao desenvolvimento da tecnologia de ponta e também da facilidade de propagação do conhecimento por meio dos meios de comunicação e de disponibilização de informação; no entanto, as respostas concretas são negativas e a temperatura do clima tem aumentado consideravelmente.

Nesse contexto há que se analisar o papel das normas de soft law, no âmbito do Direito Internacional Ambiental, como a alternativa de normatização para conter os danos ao meio ambiente, em especial ao clima. Devido ao seu caráter mais informal e não vinculante, essas normas acabam possuindo uma eficácia mais limitada do que as normas impositivas, chamadas de hard law, mas por outro lado, os instrumentos soft têm melhor aceitação e, por conseguinte, maior número de adesões.

Em outras palavras, pode-se dizer que o soft law é a solução adequada face às escolhas difíceis, como no caso de temas incertos cuja validade científica está, ainda, em discussão como é o caso das mudanças climáticas. Isso porque os objetivos dessas normas são a fixação de metas para ações políticas nas relações internacionais e também recomendações aos Estados para adequarem as normas de seu ordenamento jurídico interno às regras internacionais contidas nessas normas e, assim, constituírem um universo de normas que darão origem a um direito pragmático acerca do tema.

No entanto, o IPCC, através de seu Quinto Relatório, apresenta um cenário alarmante, o que coloca em dúvida a eficácia dos tratados internacionais e decisões das COPs para a contenção do aquecimento global. 
Nesse contexto, o IPCC, adverte que as perspectivas para os caminhos resilientes ao clima e para o desenvolvimento sustentável estão relacionadas fundamentalmente com a condição de que o mundo cumpra com a mitigação das mudanças climáticas, pois se nenhuma ação for tomada, a meta de $2^{\circ} \mathrm{C}$ acordada pelos líderes mundiais, em breve estará fora de nosso alcance e se as emissões de GEE continuarem aumentando no mesmo ritmo da atualidade, as projeções são de um aumento da temperatura global média entre 2,6 e 4,8 $\mathrm{C}$ até o final do século.

Considerando todo o explanado, a grande expectativa é o acordado na COP de número 21, em Paris, na França, ou seja o cumprimento do novo documento que promete substituir o Protocolo de Quioto e dar uma solução mais imediata para a problemática do aquecimento global: o Acordo de Paris.

\section{REFERÊNCIAS}

CALIJURI, Maria do Carmo; CUNHA, David Gasparini Fernandes. Engenharia Ambiental. Conceitos, Tecnologia e Gestão. Ed. Campos. 2012.

IPCC. Glossário, 2001. Disponível em: (http://www.ipcc.ch/pdf/glossary/ipcc-glossary.pdf> IPCC. Quarto Relatório, 2007. Disponível em: < Disponível em: <http://www.ipcc.ch/publications_and_data/ar4/syr/es/contents.html>.

IPCC. Quinto Relatório, 2014. Disponível em: < https://www.ipcc.ch/pdf/assessmentreport/ar5/syr/SYR_AR5_FINAL_full_es.pdf>

JUSTE RUIZ, José. Derecho internacional del medio ambiente. Madrid: MacGraw-Hill, 1999.

KOLB, Robert. Réflexions de philosophie du droit international. Problèmes fondamentaux du droit international public: Théorie et philosophie du droit international. Bruxelles: Bruylant, 2003.

MORAES, Giovanni. Elementos do Sistema de Gestão de SMSQRS, Sistema de Gestão Integrada. Verde Editora. $2^{a}$ Edição, V.2, 2010. Disponível em: https://books.google.com.br/books?id=1eJFN1kO74IC\&pg=PA27\&dq=efeito+estufa+sem+te $\mathrm{rra}+$ gelada $\& \mathrm{hl}=\mathrm{pt} \# \mathrm{v}=$ onepage $\& \mathrm{q}=$ efeito $\% 20$ estufa $\% 20 \mathrm{sem} \% 20$ terra $\% 20$ gelada $\& \mathrm{f}=$ false $>$ Acesso em 5 de agosto de 2015.

UN. FCCC/CP/2011/9/Add.1. Informe de la Conferencia de las Partes sobre su $\mathbf{1 7}^{\mathbf{0}}$ período de sesiones, celebrado en Durban del 28 de noviembre al 11 de diciembre de 2011. 15 de marzo de 2012. Disponível em: http://unfccc.int/resource/docs/2011/cop17/spa/09a01s.pdf 
UN.. FCCC/CP/2014/10. Report of the Conference of the Parties on its twentieth session, held in Lima from 1 to 14 December 2014. Part one: Proceedings. 2 Feb 2015. Disponível para download em: http://unfccc.int/bodies/body/6383/php/view/reports.php>.

UN. FCCC/CP/2013/10. Report of the Conference of the Parties on its nineteenth session, held in Warsaw from 11 to 23 November 2013. Part one: Proceedings. 31 Jan 2014. Disponível para download em: http://unfccc.int/bodies/body/6383/php/view/reports.php>.

UN. FCCC/CP/2012/8. Report of the Conference of the Parties on its eighteenth session, held in Doha from 26 November to 8 December 2012. Part one: Proceedings. 28 Feb 2013. Disponível para download em: http://unfccc.int/bodies/body/6383/php/view/reports.php>.

UN. FCCC/CP/2011/9. Report of the Conference of the Parties on its seventeenth session, held in Durban from 28 November to 11 December 2011. Part one: Proceedings.

15 Mar 2012. Disponível para download em:

<http://unfccc.int/bodies/body/6383/php/view/reports.php>.

UN. FCCC/CP/2010/7. Report of the Conference of the Parties on its sixteenth session, held in Cancun from 29 November to 10 December 2010. Part one: Proceedings.

15 Mar 2011. Disponível para download em:

http://unfccc.int/bodies/body/6383/php/view/reports.php> Acesso em 11 de agosto de 2015.

UN. FCCC/CP/2009/11. Report of the Conference of the Parties on its fifteenth session, held in Copenhagen from 7 to 19 December 2009. Part One: Proceedings. 30 Mar 2010. Disponível para download em: <http://unfccc.int/bodies/body/6383/php/view/reports.php>.

UN. FCCC/CP/2008/7. Report of the Conference of the Parties on its fourteenth session, held in Poznan from 1 to 12 December 2008. Part One: Proceedings. 9 Mar 2009.

Disponível para download em: <http://unfccc.int/bodies/body/6383/php/view/reports.php>.

UN. FCCC/CP/2007/6. Report of the Conference of the Parties on its thirteenth session, held in Bali from 3 to 15 December 2007. Part One: Proceedings. 14 Mar 2008. Disponível para download em: http://unfccc.int/bodies/body/6383/php/view/reports.php>.

UN. FCCC/CP/2006/5. Report of the Conference of the Parties on its twelfth session, held at Nairobi from 6 to 17 November 2006. Part One: Proceedings. 26 Jan 2007. Disponível para download em: <http://unfccc.int/bodies/body/6383/php/view/reports.php>.

UN. FCCC/CP/2005/5. Report of the Conference of the Parties on its eleventh session, held at Montreal from 28 November to 10 December 2005. Part One: Proceedings.

30 Mar 2006. Disponível para download em:

<http://unfccc.int/bodies/body/6383/php/view/reports.php>.

UN. FCCC/CP/2004/10.Report of the Conference of the Parties on its tenth session, held at Buenos Aires from 6 to 18 December 2004. Part one: Proceedings. 18 Apr 2005.

Disponível para download em: <http://unfccc.int/bodies/body/6383/php/view/reports.php>.

UN. FCCC/CP/2003/6. Report of the Conference of the Parties on its ninth session, held at Milan from 1 to 12 December 2003. Part one: Proceedings. 30 Mar 2004. Disponível para download em: <http://unfccc.int/bodies/body/6383/php/view/reports.php>. 
UN. FCCC/CP/2002/7. Report of the Conference of the Parties on its eighth session, held at New Delhi from 23 October to 1 November 2002. Part one: Proceedings. 28 Mar 2003. Disponível para download em: <http://unfccc.int/bodies/body/6383/php/view/reports.php>.

UN. FCCC/CP/2001/13. Report of the Conference of the Parties on its seventh session, held at Marrakesh from 29 October to 10 November 2001. Part one: Proceedings.

21 Jan 2002. Disponível para download em:

<http://unfccc.int/bodies/body/6383/php/view/reports.php>.

UN. FCCC/CP/2001/5. Report of the Conference of the Parties on the second part of its sixth session, held at Bonn from 16 to 27 July 2001. Part one: Proceedings. 25 Sep 2001. Disponível para download em: <http://unfccc.int/bodies/body/6383/php/view/reports.php>. UN. FCCC/CP/2000/5. Report of the Conference of the Parties on the first part of its sixth session, held at The Hague from 13 to 25 November 2000. 4 Apr 2001. Disponível para download em: <http://unfccc.int/bodies/body/6383/php/view/reports.php>.

UN. FCCC/CP/1999/6. Report of the Conference of the Parties on its fifth session, held at Bonn from 25 October to 5 November 1999. Part one: Proceedings. 21 Dec 1999.

Disponível para download em: <http://unfccc.int/bodies/body/6383/php/view/reports.php>.

UN. FCCC/CP/1998/16. Report of the Conference of the Parties on its fourth session, held at Buenos Aires from 2 to 14 November 1998. Part one: Proceedings. Disponível para download em: <http://unfccc.int/bodies/body/6383/php/view/reports.php>.

UN. FCCC/CP/1997/7. Report of the Conference of the Parties on its third session, held at Kyoto, from 1 to 11 December 1997. Part one: Proceedings. 6 Mar 1998. Disponível para download em: <http://unfccc.int/bodies/body/6383/php/view/reports.php>.

UN. FCCC/CP/1996/15. Report of the Conference of the Parties on its second session, held at Geneva from 8 to 19 July 1996. Part One: Proceedings. 29 Oct 1996 Disponível para download em: <http://unfccc.int/bodies/body/6383/php/view/reports.php>.

UN. FCCC/CP/1995/7. Report of the Conference of the Parties on its first session, held at Berlin from 28 March to 7 April 1995. Part one: Proceedings. 24 May 1995. Disponível para download em: <http://unfccc.int/bodies/body/6383/php/view/reports.php>

ODUM, Eugene Pleasants. Fundamentos de ecologia. 7. ed. Lisboa: Fundação Calouste Gulbenkian, 2004.

PAOLILLO, Fernando. Fuentes y evolución del derecho. RIDB, Ano 1 (2012), n ${ }^{\circ} 10$ internacional del medio ambiente", In: Cursos Euromediterráneos de Bancaja de Derecho Internacional, vol. II, Aranzadi, 1998.

SOARES, Guido Fernando Silva. A proteção internacional do meio ambiente. V.2. Barueri: Manole, 2003.

THIBIERGE, Catherine. Le droit souple: réflexion sur les textures du droit. RTD Civ, 2003.

VARELLA, Marcelo Dias. Direito internacional econômico ambiental. Belo Horizonte: Del Rey, 2003. 